\title{
LUXO DO LIXO: A ARTE SCRAPBOOKING COMO FERRAMENTA DE EDUCAÇÃO AMBIENTAL
}

\author{
Renata Lacerda Borges Scamati ${ }^{1}$ \\ Leonice Domingos dos Santos Cintra Lima ${ }^{2}$
}

Resumo: O sistema capitalista cuja centralidade é proporcionar lucro se expande a partir da produção e circulação de bens de consumo, potencializados pela obsolescência do que é produzido e descartado inadequadamente. Este trabalho apresenta uma ferramenta secular de arte chamada de scrapbooking, capaz de ser adaptada e utilizada como mecanismo de auxílio à propagação da educação ambiental, pois é feita com resíduos sólidos, o que contribui para a redução dos materiais que seriam descartados no meio, com uma consequente redução da agressão à biota. Com a aplicação da técnica do scrapbooking transformam-se objetos do lixo em artísticos e proporciona uma técnica de grande potencial econômico, já que é possível usála para a complementação da renda de famílias em situação de vulnerabilidade social.

Palavras-chave: Arte na Educação; Vulnerabilidade Social; Resíduo Sólido; Scrapbooking. 


\section{Introdução}

A história da humanidade está diretamente ligada à necessidade de equilíbrio do meio ambiente; é bem verdade, que a expansão desta conscientização quanto à associação indispensável entre homem e meio, ganha maior escopo na atualidade. Não que o homem, elemento "único" dotado de racionalidade, não soubesse antes dessa dependência humana, apenas não vislumbrava a finitude dos recursos naturais. Fatores econômicos ligados ao sistema de cada época da história da humanidade, fizeram com que ficassem de lado as preocupações com a manutenção do meio, abrindo espaço para a busca desenfreada do desenvolvimento a qualquer custo. Deste modo, extraiu-se do meio com maior ou menor intensidade aquilo que necessitavam naquele momento histórico para manter a vida em sociedade e no sistema capitalista, para manter a hegemonia dos que detêm os meios de produção.

O homem é o único animal que absorto de plena consciência é capaz de modificar o meio ambiente e o tem feito em benefício próprio em detrimento do próprio meio. $O$ uso desordenado dos recursos apresenta na sociedade contemporânea resultados que apontam para o comprometimento da vida no planeta: aquecimento global, doenças letais, falta de energia, escassez da água, excesso de lixo, concentração de riquezas e proliferação da miséria. Estas consequências fatais são mormente justificadas pela busca do bem-estar social para disfarçar o âmago da sua essência que se revela na primazia do lucro e o fortalecimento do capitalismo, reais prioridades deste sistema.

A busca desenfreada ao desenvolvimento econômico, a utilização desordenada e abusiva dos recursos naturais, o crescimento populacional carente de educação ambiental, são alguns dos inúmeros fatores que levaram ao uso inadequado dos recursos naturais causadores dos impactos negativos ao meio ambiente.

É sabido que recursos ambientais encontrados à disposição dos homens dos séculos passados trouxe a equivocada ideia de que os recursos naturais eram infinitos, e resultou na potencialização e avanço do desenvolvimento econômico desprovido de cuidados com o meio.

Desde as últimas décadas do século passado, a humanidade convive com as consequências desse mau uso do meio, e inicia-se especialmente no campo da educação ambiental e dos movimentos ambientalistas a jornada para tentar incutir na homem, comportamentos na relação homem/natureza que se concretizem em ações de preservação e proteção do meio ambiente até então considerados desnecessários.

Deste vértice, são utilizados habitualmente dois mecanismos sociais: a conscientização dos indivíduos através do processo de educação ambiental, e a adequação da legislação, que com o seu caráter regulador, voltada ao cumprimento da ordenação social, cria normas em torno da proteção da biota.

Entendendo-se que o caminho coativo, punitivo utilizado como mecanismo político se faz necessário devido à falta de base educacional da

revista brasileira educação ambiental 
população, neste trabalho empreendemos esforços para valorizar e revelar a educação ambiental como mecanismo preventivo de proteção da biota, assim buscamos alternativas educacionais que possam estimular crianças, jovens e educadores a utilizar materiais habitualmente descartados e revelar formas para o reuso dos mesmos.

Ao reconhecer-se a educação como o melhor caminho para a mudança de paradigmas socialmente cristalizados compreende-se também que através dela a sociedade efetivamente evita o dano (no caso específico - 0 dano à natureza) caberá a legislação, com seu aspecto punitivo, voltar-se apenas aos que não interiorizaram a importância do devido cuidado ao meio ambiente.

Neste contexto, o processo de educação ambiental, emerge como mecanismo usado para que a sociedade e o indivíduo resignifiquem sua base de valores, conhecimentos, habilidades, atitudes e competências voltadas para a exploração e proteção do meio ambiente. Apresenta-se, portanto, como lócus privilegiado de ações sobre a temática.

Condicionado à este raciocínio preventivo, encontramos ferramentas disponíveis auxiliadoras da educação ambiental, destas tomamos como objeto deste estudo a técnica de arte milenar - scrapbooking- que pode ser adaptada e utilizada com fim de preservação ambiental.

A ferramenta scrapbooking, é uma forma de expressão artística feita a partir de recortes, que pode ser adaptada utilizando resíduos, sendo desta forma um mecanismo capaz de contribuir no processo de conscientização do homem auxiliando na educação ambiental. Pode ser aplicada utilizando-se de recursos que seriam descartados e jogados nos lixões.

O uso da técnica do scrapbooking, pode despertar nos indivíduos a criatividade e capacidade de criação, estimulando-o para a elaboração de variados trabalhos com elementos corriqueiros do dia-a-dia como rótulos, embalagens, papel, papelão e/ou outros materiais que seriam descartados no meio ambiente, transformando-os em objetos de "luxo", passíveis de se constituir em geração de renda para famílias em situação de vulnerabilidade social e econômica ao mesmo tempo de corroborar com a diminuição do descarte de resíduos e coisas consideradas inservíveis para o uso humano.

\section{Revisão de Literatura}

\section{Capitalismo e Impactos Ambientais}

A visão materialista elemento fundamental da sociedade capitalistaburguesa, hegemônica na sociedade ocidental contemporânea incutiu na população a ideia de medida de valores pelos bens materiais acumulados, este modelo de sociedade assentado no capitalismo avançado e se fortalece a partir da relação produção/consumo. Esta relação vem promovendo o esgotamento das reservas naturais do planeta. 
Onde quer que tenha chegado ao poder, a burguesia destruiu todas as relações feudais patriarcais, idílicas. Estilhaçou, sem piedade, os variegados laços feudais que subordinavam 0 homem a seus superiores naturais, e não deixou subsistir entre os homens outro laço senão o interesse nu e cru, senão o frio "dinheiro vivo" [...]. Deste modo, o culto ao capital e ao consumismo impera em todos os setores e relações sociais. A burguesia rasgou o véu de emoção e de sentimentalidade das relações familiares e reduziu-as a mera relação monetária (MARX; ENGELS, 2001, p.27).

Esse sistema vigente tem suas raízes em meados do século XVIII em transição para o século XIX, perdurando até a atualidade na maioria dos países do globo. A base do sistema instituído pela burguesia gira em torno do capital, objetivando o lucro.

Pelo rápido desenvolvimento de todos os instrumentos de produção, pelas comunicações infinitamente facilitadas, a burguesia impele todas as nações, mesmo as mais bárbaras, para a torrente da civilização. Os preços baixos de suas mercadorias são a artilharia pesada que derruba todas as muralhas da China, que obriga os bárbaros xenófobos mais renitentes a capitularem. Obriga todas as nações, sob pena de arruinarem-se, a adotarem o modo de produção burguesa; obriga-as a introduzirem em seu seio a chamada civilização, isto é, compele-as a tornarem-se burguesas. Em suma, plasma um mundo a sua própria imagem (MARX; ENGELS, 2001, p.30)

Ganhando mais uma parcela da população no universo do consumismo que movimenta a mola do capitalismo, o sistema articuladamente atrela nas bases sociais a necessidade do consumo desenfreado cada vez mais motivado e estimulado pela mídia que com seu papel de ordenadora de aceitação social incute nas bases emotivas da camada trabalhadora o que vestir, o que comer, o que comprar.

[...] tal modelo de desenvolvimento econômico se funda no lucro, a qualquer custo, e este está atrelado à lógica do aumento de produção (em que os recursos naturais são utilizados sem nenhum critério; em que o ambiente é visto como um grande supermercado gratuito, com reposição infinita de estoque; em que se privatiza o benefício e se despreza e socializa o custo). Essa produção crescente precisa ser consumida. O consumo é estimulado pela mídia - especialista em criar "necessidades desnecessárias" - tornando as pessoas amarguradas ao desejarem ardentemente algo que não podem comprar, sem perceber que viviam muito bem sem aquele objeto de consumo. O binômio produção-consumo termina gerando uma maior pressão sobre os recursos naturais Revbea, São Paulo, V. 12, № 2: 34-55, 2017. 
(consumo de matéria prima, água, energia elétrica, combustíveis fósseis, desflorestamentos, etc), causando mais degradação ambiental (DIAS, 2004, p.96, grifos do autor).

Essa degradação reflete-se na perda da qualidade de vida, por condições inadequadas de moradia, poluição em todas as suas expressões, destruição de hábitats naturais e intervenções desastrosas nos mecanismos que sustentam a vida na terra. Os estudos das ciências ambientais revelam há muito que esse sistema é não-sustentável, e os sintomas dessa insustentabilidade preenchem as manchetes da mídia, diariamente, traduzidos em graves e profundas crises socioambientais, econômicas e políticas, em todo o mundo.

Nesse cenário é possível observar às sequelas do sistema capitalista, como a intensificação das desigualdades sociais, a degradação ambiental, a inversão de valores humanos e morais que regem a vida em sociedade. " $O$ atual momento histórico, caracterizado pela hegemonia capitalista, apresenta como características marcantes o desemprego, a pobreza e as desigualdades sociais em elevada escala" (BRANCO, 2010).

$\mathrm{Na}$ globalização das economias em curso no final desde o final século XX predominam as políticas governamentais favoráveis à valorização do capital em detrimento das questões humanitárias e ambientais, a centralidade da vida social neste sistema econômico/político, desloca-se do homem para o capital, do capital para o lucro exacerbado, criando entre os homens uma lacuna social intransponível, fetichizada pela ilusão da igualdade aparente disseminada midiaticamente.

O capitalismo promete o paraíso da abundância de consumo. Para obter a satisfação de todos os desejos de consumo, eles prometem a superabundância de produção, via maximização do progresso técnico. Quanto mais técnica mais produção, mais satisfação de desejos de consumo. $O$ capitalista é um sistema materialista-consumista, por excelência. Para a maximização do progresso técnico - segredo dessa promessa - é necessário, segundo eles, a sobrevivência dos mais competentes e a exclusão/sacrifício dos mais fracos. Em virtude disso, dizem ele que os sacrifícios impostos à população pobre são sacrifícios necessários (SUNG, 1995).

Ante esta realidade histórica alguns aspectos gerais podem ser abordados como sequelas do sistema vigente e são demonstrados nos estudos de Freitas (2012) que apresenta a Divergência entre Capital e Trabalho como processo derivado da luta pelos interesses da classe trabalhadora e os detentores do capital e dos meios de produção, exercem a exploração da mãode-obra com objetivo de adquirir uma lucratividade maior e assim acumular capital; a Degradação Ambiental como uma das consequências do sistema capitalista; está ligada à produção em massa e ao consumo na mesma proporção; retira-se da natureza a matéria-prima da produção deixando um saldo de devastação profunda no meio-ambiente. 
Para o mesmo autor, a Intensificação das Desigualdades Sociais como resultado da busca por lucro à custa da exploração do trabalho aumenta a disparidade econômica existente na medida em que concentra as riquezas nas mãos de poucas pessoas e a Extinção dos Valores Humanos que resulta da crença de que a posse de bens materiais igualam ou diminuem as diferenças sociais, distancia cada vez mais o homem dos valores humanos; as relações humanas como amizade, solidariedade, companheirismo são constantemente ignoradas.

Estes elementos, que compõem o tecido da sociedade contemporânea, desenham um futuro onde a vida depende cada vez mais do respeito à natureza, sua proteção e preservação; depende ainda do reajuste da visão que distorce a compreensão do visa em sociedade e quais os elementos centrais e fundantes desta.

\section{Lei Ambiental: a busca legal da ordenação social}

As sequelas geradas pelo modelo social adotado e instituído mundialmente acarretaram mudanças não só nos aspectos das relações sociais como também ambientais. Como medida de ordenação social o Estado intervém criando legislações específicas buscando organizar a vida em sociedade adequando-se ao bem comum. No âmbito ambiental, frente ao choque da devastação causada pelo uso inadequado dos recursos naturais, deparou-se como a necessidade de normatizar o comportamento humano ao se relacionar como a biota.

Sob este vértice, relacionando a vida humana à necessidade do equilíbrio da biota, nasceram as leis para ordenar os atos do homem sobre o meio.

O Brasil, no âmbito do meio ambiente, possui normas apreciadas mundialmente, principalmente por ter criado leis especiais. A legislação ambiental pautada na lei 6.938/81 traz um caráter normativo especial legal, fugindo à regra do direito comum brasileiro. Na legislação ambiental nacional:

A responsabilidade objetiva ambiental significa que quem danificar o ambiente tem o dever jurídico de repará-lo. Presente, pois, o binômio dano/reparação. Não se pergunta a razão da degradação para que haja o dever de indenizar e/ou reparar. Não interessa que tipo de obra ou atividade seja exercida pelo que degrada, pois não há necessidade de que ela apresente risco ou seja perigosa (MACHADO, 2007, p.735)

O caráter punitivo ordenador da norma existe e deve ser cumprindo, no entanto, já se tem noção de que a prevenção é melhor medida e traz resultado mais eficiente, tendo em vista que a prevenção evita a existência de problemas que podem tornar-se insolúveis em casos como as catástrofes ambientais e o risco eminente à própria vida humana que estes danos podem provocar. 


\section{Educação: elemento de transformação social e formação do pensamento social}

A educação é instrumento de transformação social, tendo em vista que através da educação edificamos e enobrecemos o saber e o homem, sendo sujeito de direito pensante, se reflete como elemento transformador, a educação escolar contribui para a formação do indivíduo em sua capacitação de base cientifica, social e cultural.

Inúmeras correntes do pensamento existem acerca da influência direta dos interesses dos sistemas que vigem em cada época sobre a educação como corrente entre a ideologia política hegemônica e a verdadeira formação de base do indivíduo. Assim, a escola exerce papel fundamental na formação do ser e suas concepções de mundo.

Sob este prisma, o momento socioeconômico vivido em cada época da história da humanidade tem influência direta nos métodos de ensino e na formação do pensamento social.

Porém, a escola pode extrapolar a esfera política e econômica não se limitando a ser apenas um espaço de reprodução de um modelo econômico que se contenta em buscar e formar o que o mercado exige.

Em um mundo marcado pela fluidez de fronteiras, quer no sentido econômico, quer no sentido cultural, onde o tempo e espaço são redimensionados pela divulgação crescente os recursos tecnológicos, configura-se um novo cenário cujo pano de fundo pode ser representado por um emaranhado de fios urdidos em uma teia que tende a se tornar cada vez mais onipresente. Muitas questões se colocam na arena educativa, provenientes das tensões deste cenário complexo, em que significados locais e globais são expressos, num turbilhão de sons e vozes, e que, apesar de todo avanço científico, revelam a existência de processos de profunda desigualdade social (CANDAU, 2002, p.13).

Mészáros (2009) esclarece que com a massificação das ideias sociais, o povo aliena-se no superficial uso tecnológico e mercadológico, incutidos pela cultura dominante do ter e não do saber:

Vivemos atualmente a convivência de uma massa inédita de informações disponíveis e uma incapacidade aparentemente insuperável de interpretação dos fenômenos. Vivemos o que alguns chamam de "novo analfabetismo" - porque é capaz de explicar, mas não de entender -, típico dos discursos econômicos. [...] explicar é reproduzir o discurso midiático, entender é desalienar-se, é decifrar, antes de tudo o mistério da mercadoria, é ir além do capital (MÉSZÁROS, 2009, p.17). 
Agregado a ideia de que a formação acadêmica e social do indivíduo tem relação direta com a produção e o mercado de trabalho, confirma-se a premissa de que dos bancos escolares é que saem à mão de obra produtiva, sendo qualificadas conforme a necessidade do sistema que impera.

Falar em novo perfil de mão-de-obra qualificada remete à discussão acerca da adequação da formação geral e profissional desta mesma mão-de-obra, estabelecendo-se assim uma ponte entre o plano econômico e o campo da educação. [...]. Para uma visão economicista e tecnicista, a escola deve estar fundamentalmente subordinada às exigências do mercado de uma sociedade capitalista, entendida agora não mais apenas nos limites de suas fronteiras nacionais, mas em sua dimensão planetária. Para outros, a escola não pode se limitar exclusivamente ao papel de fornecedora de mão-de-obra qualificada, trazendo para o debate a necessidade de valorizar outras de suas funções e papéis que extrapolariam a dimensão econômica (CANDAU, 2002, p.23).

A educação da gente comum, dos trabalhadores, na visão dos teóricos da economia política, é defendida apenas como mecanismo de liberação dos obstáculos que se podem opor a essa marcha inexorável do progresso econômico (BUFFA, 2010, p.60). Dando continuidade à ideia expressada:

Um povo instruído e inteligente é, além disso, geralmente mais decente e ordeiro do que o povo ignorante e estúpido [..]. São (cada um individualmente) menos suscetíveis de ser desencaminhados para qualquer oposição injustificada, ou desnecessária às medidas do governo" (SMITH, 1981, p.422 apud BUFFA, 2010, p.61).

Manter a massa instruída segundo o interesse exposto é manter a ordem pela consciência da necessidade de sobrevivência que se tem enquanto ser vivo, de modo a evitar que transtornos desnecessários ao poder dominante se apresentem, fazendo com que, quem pode vender sua mão-de-obra, o faça sem se debater, quem consegue qualificar sua mão-de-obra que venda a preço mais elevado, mas que a venda e, desta forma mantenha o sistema em ordem.

O objetivo central dos que lutam contra a sociedade mercantil, a alienação e a intolerância é a emancipação humana. A educação, que poderia ser uma alavanca essencial para a mudança, tornou-se instrumento daqueles estigmas da sociedade capitalista: "fornecer o conhecimento e o pessoal necessário a maquinaria produtiva em expansão do sistema capitalista, mas também gerar e transmitir um quadro de valores que legitima os interesses dominantes". Em outras 
palavras tornou-se uma peça do processo de acumulação de capital e de estabelecimento de um consenso que torna possível a reprodução de um injusto sistema de classes. Em lugar de instrumento de emancipação humana, agora é mecanismo de perpetuação e reprodução desse sistema (SADER, 2009, p.15 apud MÉSZÁROS, 2009, p.15).

Seguindo a linha do saber voltado a verdadeira formação do ser social, que convive em sociedade, que se constitui de valores éticos, morais e não apenas 0 indivíduo como elemento consumidor propagador das ideias sistêmicas, desenvolves teorias voltadas a reorganização dos conteúdos escolares, buscando novos modelos e aparatos de constituição do saber critico, indispensável ao momento sócio/cultural vivido.

Azevedo (1943) na década de 40 do século passado aborda a necessidade de se apresentarem ideias sobre educação que apresentassem conteúdos para uma análise de possível reorganização, seus ensinamentos refletem sobre a necessidade de partir para ideia novas e concepções desagregadas da figura estatal.

\section{Educação Ambiental: elemento Indissociável da preservação e proteção da biota}

A atual situação vivenciada, em nivel global, referente a degradação ambiental, associada ao fim capitalista da produção em série e consumo desenfreado, desencadearam inumeras ações voltadas para a proteção do meio ambiente, reestruturação industrial, focadas no desenvolvimento sustentavel e na educação ambiental.

Buscar formas de ensino que contribuam para uma base sólida do ser humano na sua relação com a natureza, estruturada nas pessoas é mecanismo indispensavel para sucesso futuro de qualquer alternativa implantada, seja do ponto de vista da educação formal, seja como educação para a vida.

A educação ambiental (EA) vem sendo incorporada como uma prática inovadora em diferentes âmbitos.[...] o novo de uma EA realmente transformadora, ou seja, daquela EA que vá além da reedição pura e simples daquelas práticas já utilizadas tradicionalmente na educação, tem a ver com o modo como esta EA revisita esse conjunto de atividades pedagógicas, reatualizando-as dentro de um novo horizonte epistemológico em que o ambiental é pensado como sistema complexo de relações e interações da base natural e social e, sobretudo, definido pelos modos de sua apropriação pelos diversos grupos, populações e interesses sociais, políticos e culturais que aí se estabelecem (CARVALHO,2006, p.106). 
A consciência do todo leva a eficiência de partes e ações isoladas, em outras palavras, formando cidadãos cientes da sua relação como meio e com a sociedade consegue-se criar bases solidas de ações individuais e coletivas, de modo que a sociedade passe a incorporar que o equilibrio da biota é necessario para a vida do ser humano em sua plenitude passando assim a cuidar do meio ambiente e da preservação da vida da espécie humana e das demais.

Neste contexto, a educação ambiental configura-se como um mecanismo eficaz de alcance de tal conscientização, de modo que nas palavras de Dias (2004) oferecem a real dimensão das possibilidades da educação:

O Desenvolvimento Sustentável salta da utopia para assumir o papel de estratégia para a sobrevivência da espécie humana, e a Educação Ambiental passa a representar um importante componente dessa estratégia, em busca de um novo paradigma, de um novo estilo de vida (DIAS, 2004, p.97, grifos do autor).

A educação ambiental está relacionada a uma perspectiva política abrangente, incorpora a proposta da construção de sociedades socioambientalmente sustentáveis e funciona como tema inerente à formação de estudantes desde as séries iniciais até a constituição das matrizes curriculares das várias áreas da formação profissional.

No Brasil a Educação Ambiental tornou-se lei em 1999 (Lei n. 9.796 transcrita no capitulo 10 - Legislação Ambiental Brasileira) como componente essencial e permanente da educação nacional, em todos os níveis de modalidades do processo educativo, em caráter formal e nao-formal.

Deve-se considerar ainda que a educação ambiental, pela seriedade de sua proposta, e pela urgencia na solução de problemas, não pode ser esporádica. Seu caráter essencial é a permanência e a continuidade, a fim de manter o indivíduo e a sociedade atualizados com a dinâmica do meio ambiente global.[...]. A solução está na prevenção proporcionada pela conscienteização pela educação ambiental em todos os níveis de ensino (BRASIL, 2011, p.32).

Sob este paradigma não basta possuirmo no Brasil uma legislação teórica pertinente e admirável, tendo em vista que a mesma punirá aquele que já alterou de modo negativo o bem ambiental, necessário instituirmos de modo permanente e atualizado a educação ambiental, posi desta forma estarem trando da prevenção à lesão.

Trabalhar com educação ambiental é estimular a associação do individuo, integrando-o no meio social e ambiental, instituíndo no ser a sua 
capacidade de interação com o todo, estabelencendo bases de respeito e consideração recíprocas e para o pensamento coletivo.

Assim, inúmeros meios e atividades podem ser utilizados para se aplicar e estimular a educação ambiental em todos os setores, desde as bases de educação fundamental como em ONGs - Organizações Não Governamentais, grupos, associações, universidades, ela se adequa a todas as classes e idades.

\section{A arte na educação: expressão de cultura e valores humanos}

A arte, independente da época social, amplia o universo do saber crítico, pois estimula os sentidos, reflete o intimo, exterioriza o subjetivo, materializa a visão além de estimular a coordenação, instigar o instinto, apurar a tecnica e edificar o espírito.

O uso da arte ultrapassa as linhas do auxilio da socialização; ela reflete as marcas de uma época, os costume, as tradições. Expõe o individuo a um momento de criação ao qual o resultado sera único, individualizado carregado do momento, da emoção e da doação.

A arte é movimento na dialética da relação homem-mundo [...]. Em cada sociedade e em cada época, as obras artíticas são também sínteses que dependem das trajetórias pessoais de quem as fez e de suas concepções sobre o ser humano, o gosto, os valores etc. Logo, os artistas, autores, em suas relações com a natureza e a cultura produzem obras que se diferenciam formal e expressivamente (FUSARI, 2001, p.23).

A carga expressiva exteriorizada no processo de criação é a explanação do individuo criador, das influências internas, do campo íntimo do indivíduo e externas oferecidas pelo meio. Deste modo, a arte no âmbito escolar contribui para a formação social do cidadão, trabalhando nele aspectos de liberação de sua visão crítica e social. "Tem a possibilidade de contribuir para a preparação de indivíduos, que percebam melhor o mundo em que vivem, saibam compreendê-lo e nele possam atuar" (FUSARI, 2001, p.24).

A arte possui muitas vertentes a serem utlizadas na formação do indíviduo, podendo ser direcionada aos problemas sociais vivenciados, conscientizando o ser, instruindo-o ao saber critico, podendo direcioná-lo a determinado foco social. Assim, a educação ambiental, tão necessaria no momento social atual, pode ser ensinada e exteriorizada também através da arte, possibulitando uma vivencia efetiva, sensível e uma consciência plena em relação as questões ambientais.

Dentre as diversas possibilidades de utilização da arte como ferramenta de educação ambiental este trabalho tem como objeto principal a técnica do scrapbooking. 


\section{Scrapbooking: a arte milenar a serviço da educação ambiental}

A arte do "scrapbooking" embora tenha sido popularizada no século passado, é uma arte de origem milenar, muito utilizada em diversos momentos da história da humanidade, vindo apenas a sofrer alterações conforme a disponibilidade de novos meios e materiais que possibilitaram sua releitura.

Consta que na antiguidade era utilizada para a composição de memórias e recordações, buscando registrar momentos, sentimentos, guardar lembranças, objetos dentro de álbuns memoriais compostos por inúmeros elementos interligados por um mesmo contexto. Hoje, se popularizou como um hobby e é utilizado para registrar momentos marcantes onde se pode guardar os elementos que compõem a situação vivenciada e que se busca eternizar junto com o principal elemento de composição dos álbuns scrapbooks de hoje, as fotografias.

$\mathrm{Na}$ história milenar desta arte tem relatos de origem anterior ao nascimento da própria fotografia; de modo que os momentos eram registrados e guardados conforme a disponibilidade de recursos de cada época.

No início da era moderna os livros de relatos utilizados para registro dos momentos corriqueiros, significantes chamados "Commonplace Books", um tipo de "álbum" onde as pessoas escreviam poemas e anotações. Havia também, o chamado "Álbum dos Amigos", onde se registravam pensamentos, confissões, sendo costume da época a utilização da colagem de pedaços de cabelos de amigos nesses diários, como forma de recordação acompanhada por dedicatórias.

Os primeiros diários e livros eram decorados com pedaços de tecidos e papeis disponíveis, ali as pessoas anotavam as viagens que faziam, as impressões sentidas e tudo que reavivasse sentimento eternizado.

Segundo Diniz (2014) nos Estados Unidos, a arte do scrapbooking chegou há mais de cem anos, desenvolvendo-se, principalmente, no Norte, em regiões como Salt Lake City, no Estado de Utah, onde se concentram muitas famílias da religião Mórmon, haja vista que esta religião valoriza a preservação da história de seus descendentes, foi da tradição Mórmos surgiu o nome "scrapbooking" ou livro de retalhos.

Os primeiros álbuns, datam do ano de 1800 onde as as pessoas colecionavam citações, poemas, cartões religiosos, recortes de jornal e outros elementos que representassem algum momento especial ou pessoa querida.

Em 1825, foi impresso o primeiro livro de scrapbooking chamado "The Scrapbooking". Nele foram publicadas ideias de como usar recortes de jornal para preencher um álbum em branco.

No entanto, o scrapbooking tornou-se popular depois da publicação de um livro chamado "Manuscript Gleanings and Literary Scrap Book" de John

\footnotetext{
${ }^{3}$ A terminologia scrapbook vem do inglês e traz significado de álbum de recortes, ou livro de recortes.
}

revista brasileira educação ambiental 
Poole, em 1826. Este livro era uma coleção encadernada de poemas impressos e gravuras, além de conselhos sobre como conseguir organizar os scraps 4 .

Por volta de 1850, a sala de desenho do scrapbooking era o centro das discussões e trocas sociais. Estes locais eram usados para compartilhar pensamentos e sentimentos e tornaram-se lugares para se gravar histórias familiares e memórias especiais. Foram criados livros que eram mantidos em família por muitos anos. Neste momento, criar livros de recorte virou moda entre os americanos de classe-média.

O aumento do interesse das pessoas pelo scrapbooking os fabricantes destes materiais correram para atender a demanda e começaram a produzir uma enorme variedade de produtos que poderiam recortados e colados nos álbuns.

Em meados de 1857 as empresas começaram a produzir álbuns de couro com páginas impressas dedicadas a vários temas. Estas páginas eram decoradas com imagens de pássaros e flores, bem como tinham espaço para colocar fotografias e para fazer pinturas de aquarela e desenhos com lápis.

No entanto, o scrapbooking começou a perder sua popularidade no início de 1900, devido às restrições econômicas que se seguiram à Primeira Guerra Mundial. A recessão que se seguiu, forçou muitas empresas relacionadas ao scrapbooking sair fora dos negócios.

O ano de 1980 foi decisivo na história do scrapbooking moderno. Neste ano, Marielen Christensen compartilhou 50 volumes dos livros de memórias de sua família na Conferência Mundial Sobre Recordes, em Utah. Os álbuns geraram tanto interesse que a família Christensen abriu a primeira loja de varejo voltada especificamente para comercialização de materiais para montagem de álbuns de scrapbooking.

A partir de 1990, com a explosão de publicações sobre idéias e materiais, que o scrapbooking ganhou velocidade e se tornou um dos mais crescentes passatempos da América. Graças a Internet o scrapbooking passou a ganhar popularidade no restante no mundo.

Hoje a arte do scrapbooking se difundiu mundialmente, adquirindo milhões de adeptos que buscam guardar suas recordações em livros, álbuns que unem fotografias e itens variados.

A possibilidade de se utilizar da técnica do scrapbooking, materiais inservíveis é muito rica no sentido de criar novas possibilidades de redução de descartes e conscientização ambiental.

Sob este ângulo, aplicar-se a técnica da arte scrapbooking aos resíduos gerados corriqueiramente, que seriam descartados ao meio se

\footnotetext{
${ }^{4}$ Os scraps eram pedaços de papel impressos, frequentemente cobertos com desenhos enfeitados. $O$ mais interessante é que os adesivos remanescentes dos scraps do século XIX ainda podem ser adquiridos em lojas de scrapbook e em websites (website especializada em scrapbook "violette stickers").

Revbea, São Paulo, V. 12, № 2: 34-55, 2017.
} 
juntando as pilhas de materiais que danificam $o$ meio ambiente $e$ consequentemente prejudicam a vida em todas as suas formas é agregar redução de objetos descartados, ao trabalho de arte com todos os seus benefícios íntimos e sociais na formação do ser e ainda se obter um resultado final que além de visualmente tão nobre quanto aos álbuns feitos com adornos industrializados é possível ainda contribuir na renda familiar.

\section{Metodologia}

Estudar e apresentar o diálogo da arte-educação como contributo para a proteção e preservação ambiental desdobrou-se a partir da investigação teórica sobre o scrapbook, expressão da arte milenar já conhecida pela pesquisadora, com a finalidade de adaptá-la até que pudesse ser usada como ferramenta para a educação ambiental.

Inicia-se, pois, com revisão de literatura que revela os elementos fundantes da sociedade contemporânea, que resultou na compreensão necessária para o entendimento da urgência de intervenções que possam contribuir para a minimização do impacto na questão ambiental. Assim, buscamos autores cuja constituição do sistema capitalista fosse seu objeto de estudo. A assentamos nosso olhar a partir da teoria crítica perpetrada nos estudos marxistas. A revisão de literatura e a necessidade de aprofundamento nas questões elementares da pesquisa envereda-nos no estudo da arte e da educação, no diálogo profícuo entre os dois campos do conhecimento como possibilidades de legitimação de novos paradigmas a partir da articulação entre as duas fontes do conhecimento. Encontramos na técnica de arte milenar scrapbooking- possibilidades de uso como ferramenta de fácil aplicação, tanto como componente curricular nas escolas, ou como estratégia para geração de renda de famílias em situação de vulnerabilidade social, uma vez que na técnica pode-se utilizar recursos simples e corriqueiros, do dia-a-dia, descartados ou coletados em coleta de lixo seletiva.

A juntada de material para a confecção do álbum scrapbooking foi feita com a utilização de restos, de resíduos do nosso cotidiano, com objetos que se encontram a disposição, descartados nas ruas, nos lixos, utilizados pela sociedade e despejados no meio ambiente.

\section{O Exercício da Técnica: coleta dos elementos e a transformação do lixo em luxo}

A arte do scrapbooking feita através de materiais que seriam despejados no meio ambiente, é muito rica em criatividade e estímulos, pois contribui para uma visão inovadora ao objeto que se destinaria ao desuso. 


\section{A coleta do material:}

Para a confecção de um álbum scrapbooking com resíduos corriqueiros é necessária à coleta de materiais em desuso jogados em gavetas, que seriam descartados ao lixo ou que já foram descartados na coleta seletiva, como botões, fitas, sacolas de lojas, restos de embalagens, palitos, barbantes, restos de quebra-cabeça velho, sobras de alfabetos, imagem fotográfica etc. Válido ressaltar que qualquer objeto pode ser utilizado desde que sobre ele se possa trabalhar criatividade e técnica.

\section{Desenvolvimento da técnica:}

Para a confecção do álbum uma base de papel é necessária tendo em vista que sobre ela todo o trabalho é confeccionado (Figura 2). Uma imagem que se busca destacar é colocada como elemento do trabalho, e sobre ela os materiais que iriam para o lixo (Figura 1). Aos resíduos selecionados podem ser aplicadas inúmeras técnicas de dobragem, colagem, de fácil acesso bem como apenas podem ser sobrepostos. Aqui mora a riqueza da técnica que é de livre execução, estimulando a capacidade de criação. A pagina demonstrativa traz a aplicação de uso de sacolas comerciais trabalhadas para formar uma flor, feita a partir de desenhos e recortes de coração (Figuras 4 e 5), bem como apenas a sobreposição de resíduos sobre a imagem feitos apenas da livre criação (Figuras 7, 8 e 9).

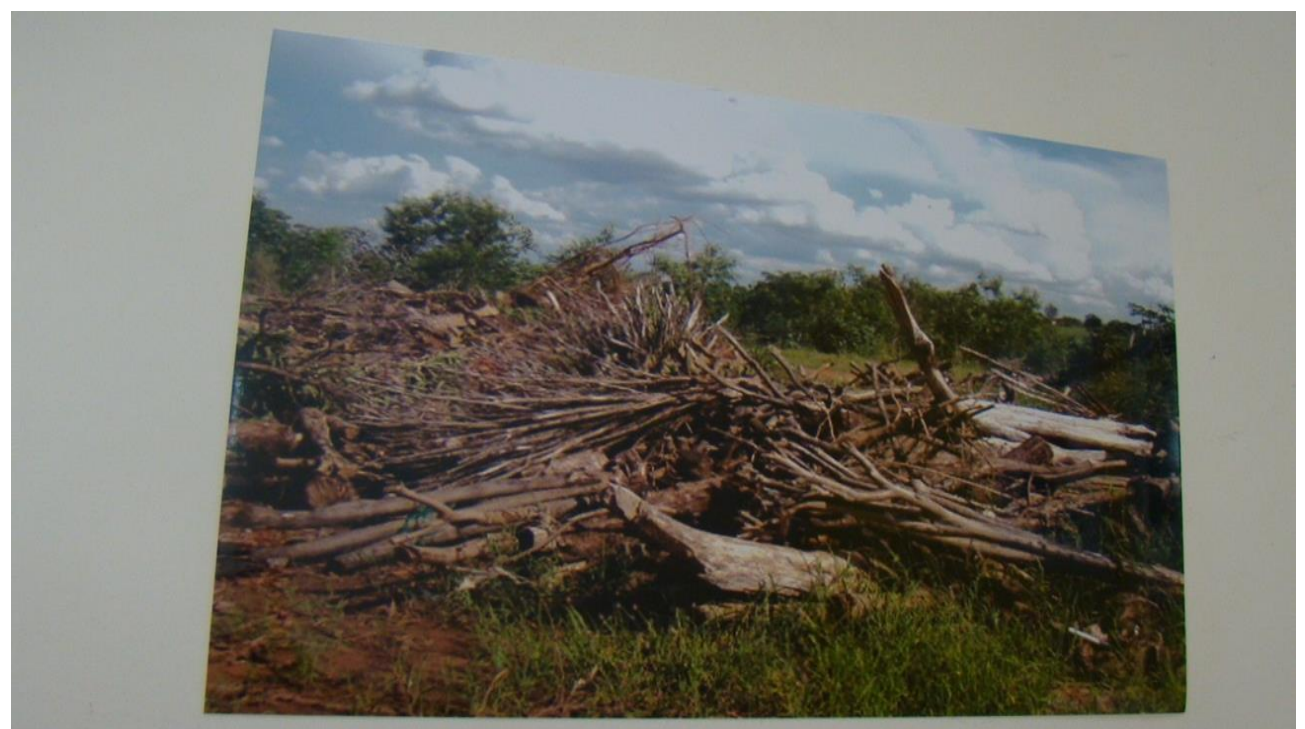

Figura 1: Fotografia selecionada para compor a página de scrapbooking. 


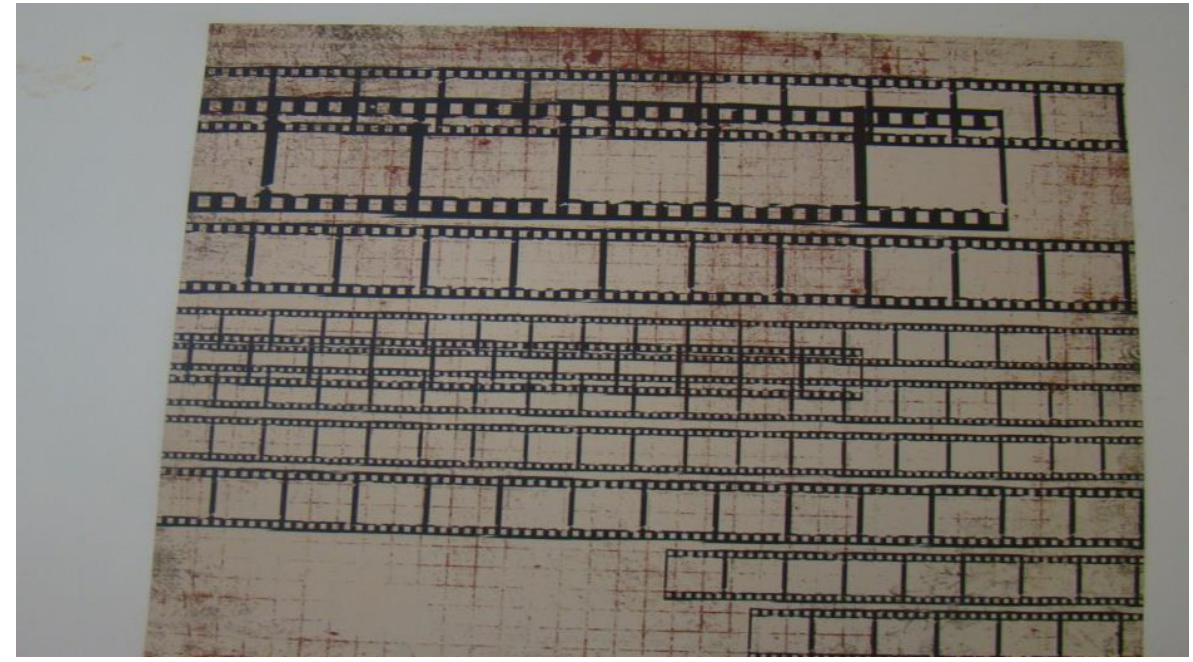

Figura 2: Papel de scrapbooking utilizado de base para compor a arte.

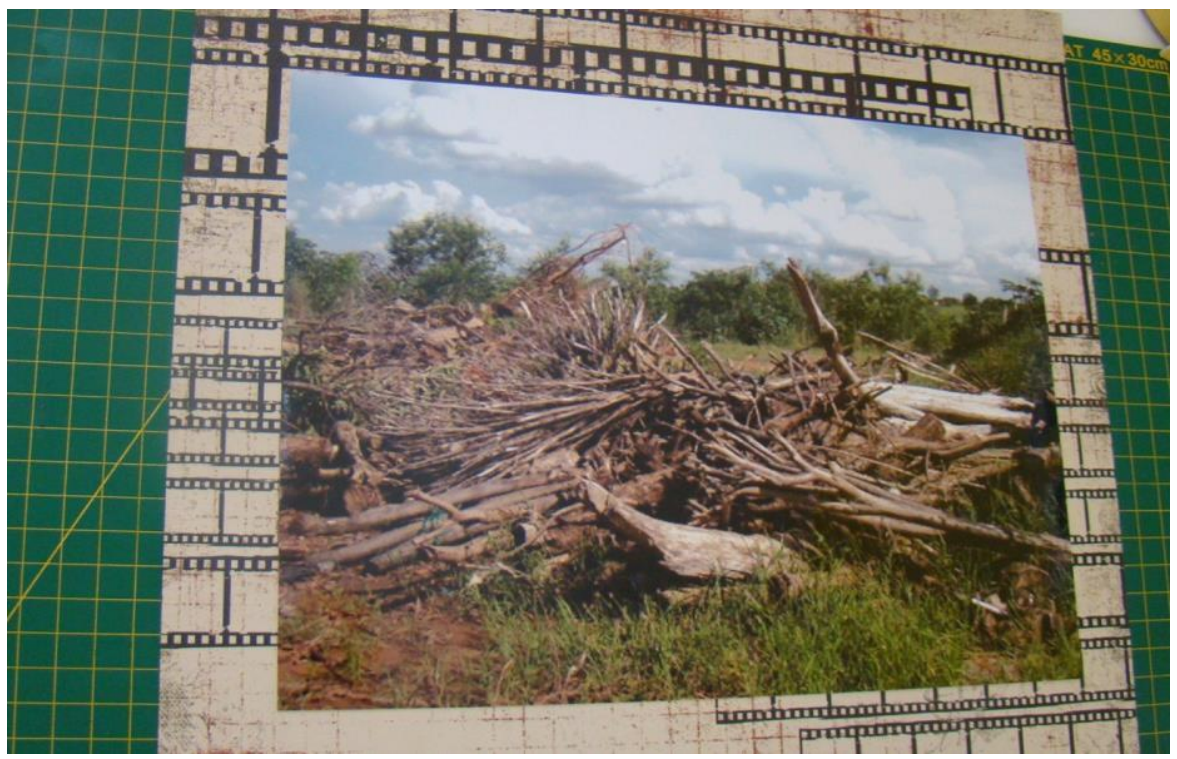

Figura 3: Resultado da fotografia colada com fita dupla face na página de scrapbooking.

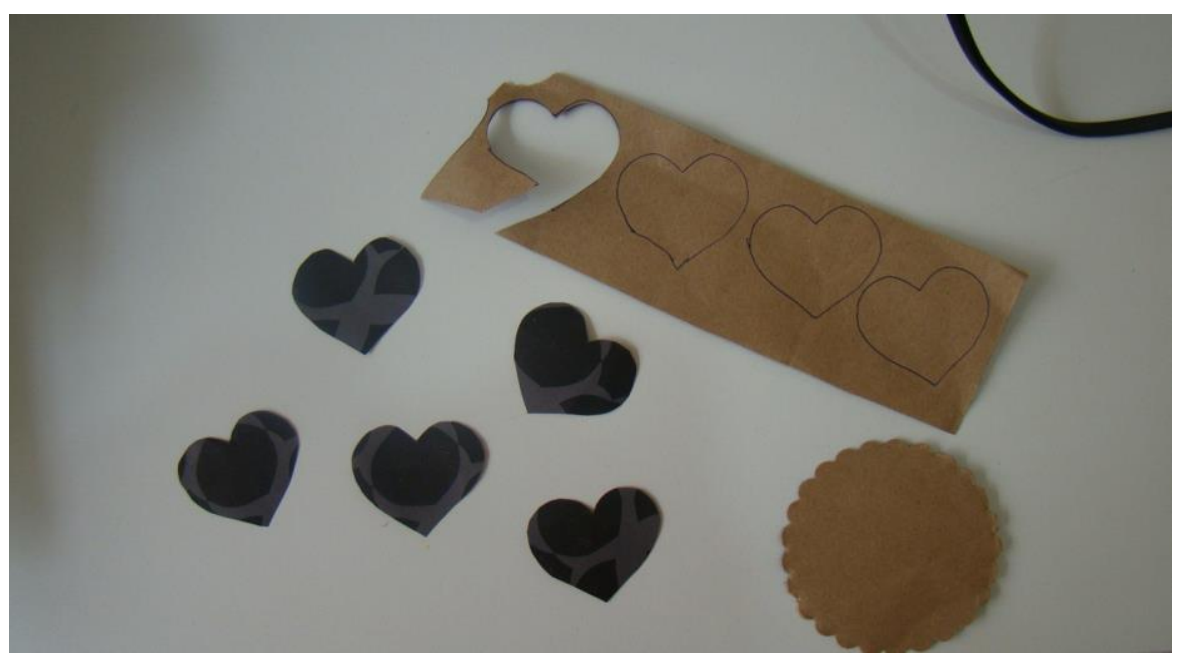

Figura 4: Recorte de corações e círculos feitos em resíduo de sacola de papel.

Revbea, São Paulo, V. 12, № 2: 34-55, 2017. 
Dobre as pontas dos corações para dar volume e criar pétalas, cole uma a uma sobre o círculo para formar uma flor (Figura 5):

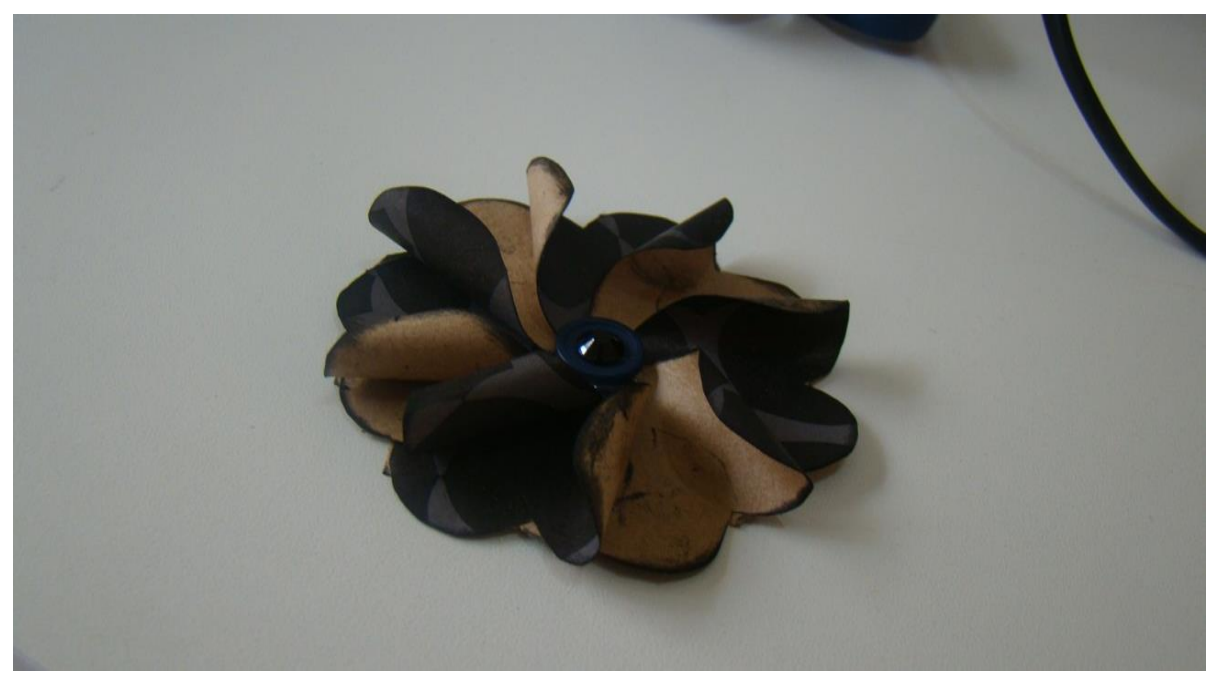

Figura 5: Flor feita com os corações recortados do resíduo sacola.

Qualquer material que seria descartado tem potencial para ser transformado pela técnica do scrapbooking, a próxima flor foi elaborada a partir de alças de sacola, sobras de quebra-cabeça, parafusos e sobras de botão (Figura 6):

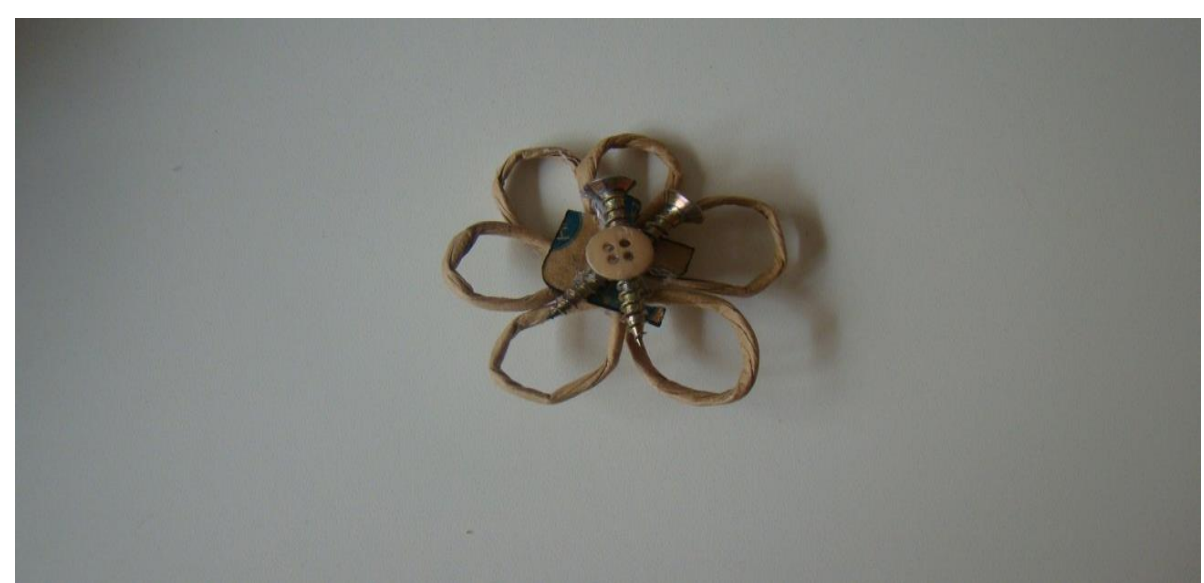

Figura 6: Flor feita com o uso dos resíduos alças de sacolas, quebra-cabeça, parafusos e sobras de botões.

Com o uso da criatividade vá sobrepondo os resíduos sobre a página de scrapbooking para criar texturas e formas.

Junte sobras de alfabeto, improvise letras para criar as palavras desejadas.

Resultado de página de scrapbooking feita com objetos de descarte (FIGURAS 7, 8 e 9):

Revbea, São Paulo, V. 12, № 2: 34-55, 2017. 


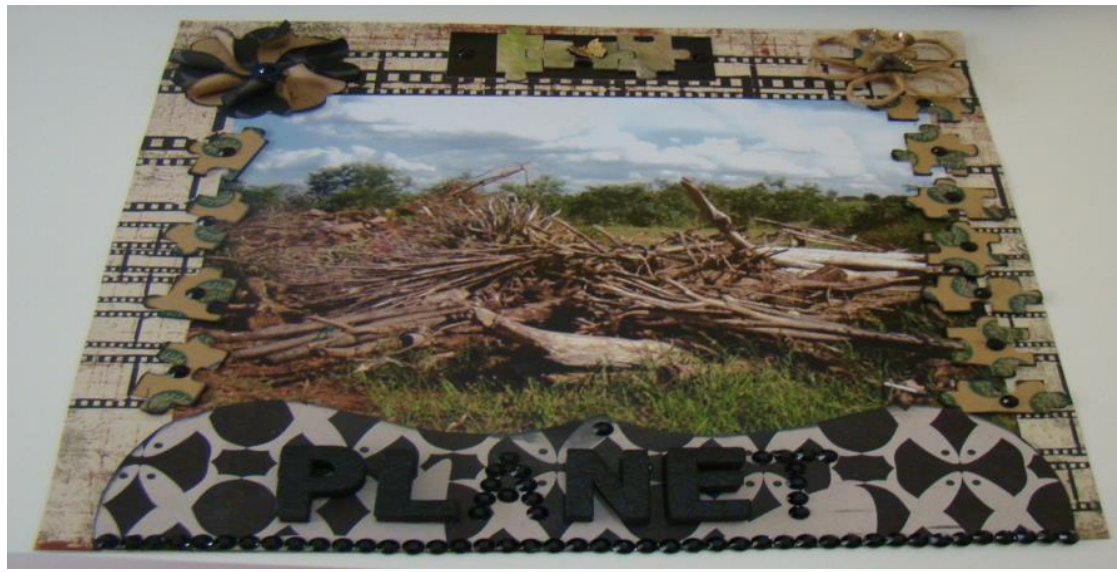

Figura 7: Página de scrapbooking feita com uso de resíduos.

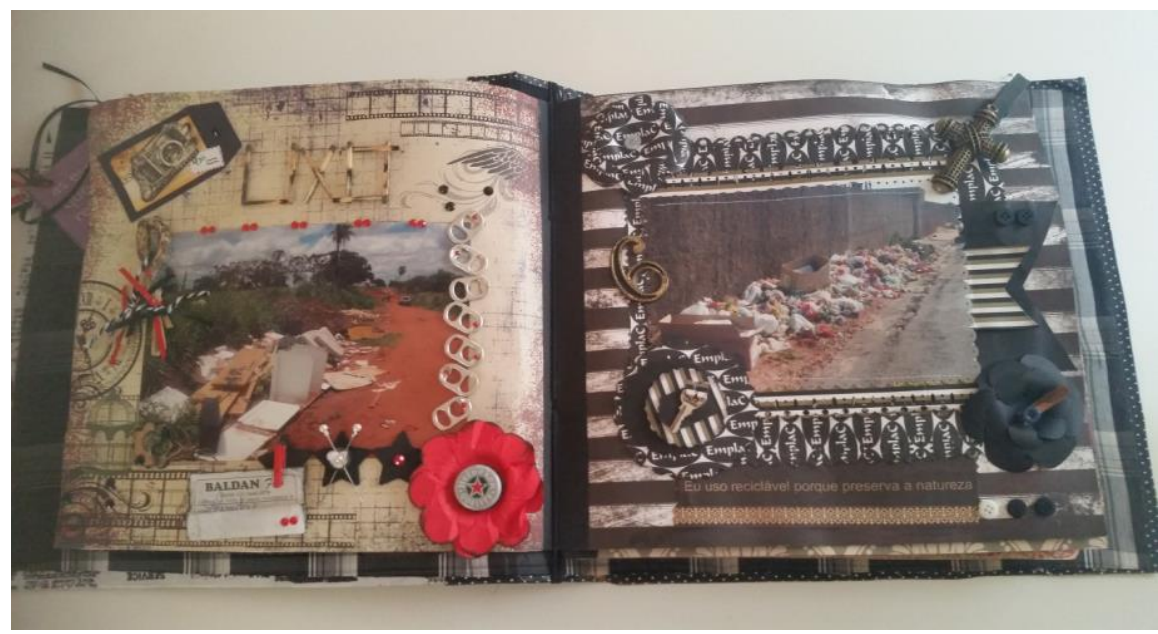

Figura 8: páginas de scrapbooking feitas com resíduos de papel, palitos de fósforos, lacres de latas, tampinha de garrafa, chaves, números, prendedor, sobras de botão, alfinetes, barbantes.

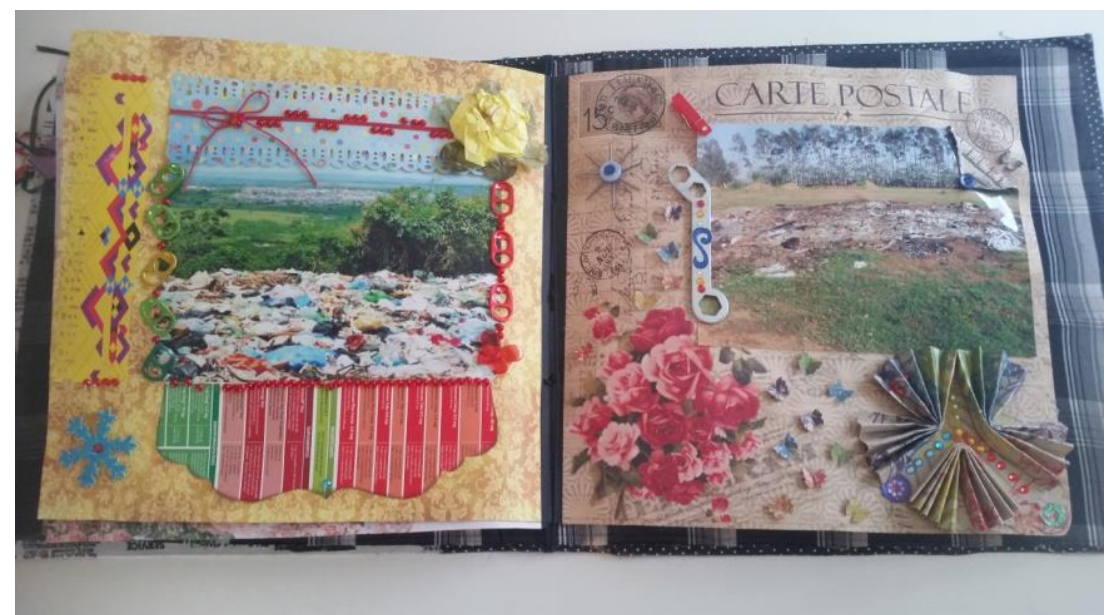

Figura 9: páginas de scrapbooking feitas com resíduos de papel, barbante, lacres coloridos de latas, forminhas de doces, chave de fenda, pregos, botões, prendedores. 


\section{Discussão}

A discussão a que se almeja demonstrar é a apresentação das visões doutrinárias quanto aos paradigmas sociais/educacionais impostos à sociedade voltada aos interesses do sistema vigente, articulando a importância da educação bem como a exteriorização desta através da arte; o que influência, trabalha e leva ao desenvolvimento do indivíduo em formação, abrindo vertentes de um cidadão critico, seguro, criativo e enriquecido na sua estima. $O$ intuito se estende à discussão da necessidade da formação do sujeito ecológico, de modo que se apresenta através da técnica milenar de arte do scrapbooking a possibilidade de auxiliar como ferramenta inovadora na educação ambiental.

Ao se utilizar a técnica do scrapbook, coloca-se a disposição da sociedade a expressão da arte como forma de reutilização de objetos de descarte e introduzi-la como conteúdo para a educação ambiental em trabalhos com jovens, crianças, adultos no ambiente familiar, estimulando a criação nos indivíduos e os levando a cuidar do meio ambiente e gerar uma fonte de renda as famílias socialmente desfavorecidas.

\section{Conclusão}

A sociedade recebe em cada época vivida uma carga de valores, conforme o sistema que lhes rege.

Hoje com os fins sistêmicos voltados ao lucro desmedido, a cultura do ter predomina a do ser nos moldes sociais, de forma que o acumulo de mercadorias se estende sobremaneira, fazendo com que o indivíduo consuma mais e gere mais lixo e consequentemente se utilize mais dos recursos naturais para a produção em série almejada.

Como propagadora do intuito do capital, as escolas inevitavelmente recebem a ordenação Estatal, conduzindo seu público a lógica cultural predominante.

No entanto, ao se falar em educação se tem por base a formação do ser social, não apenas aos saberes técnicos, mas da condução de um elemento social.

Recursos diversos estão disponíveis para estimular e conduzir nossos pequenos cidadãos dentro desta consciência enquanto ser social em contato com outros indivíduos e com o meio. Para romper com paradigmas que vislumbram a escola apenas como espaço de reprodução do sistema, é que emerge como necessidade urgente buscar caminhos para a educação. Refletir sobre novas educações, apresentar novas tendências, descobrir novos métodos, desenvolver técnicas, sair dos muros escolares, expandir ideias, contribuir socialmente a formação do saber e explorar o meio e a sociedade como objeto de efetivo aprendizado é o papel (ou pelo menos a utopia que se espera) do educador, contribuir à educação completa de formação do ser social.

Revbea, São Paulo, V. 12, № 2: 34-55, 2017. 
Esta busca se funda na necessária consciência da interação homem/homem, homem/mundo, formando seres humanos dotados do saber social e das relações que o indivíduo tem como meio em que ele vive.

Visto que o estimulo exagerado ao consumo desenfreado deixa a desejar à conscientização do indivíduo quanto a real importância do equilíbrio da biota.

Deste vértice, encontrar mecanismos que auxiliem na formação do sujeito ecológico incentivando e propagando a educação ambiental é caminho imprescindível na esteira do desenvolvimento de uma base de formação sustentável.

Assim, se vivemos hoje em um planeta que tem uma porcentagem baixíssima de reciclagem quanto ao lixo gerado, então porque não associar uma técnica milenar de arte com a necessidade e disponibilidade de recursos do momento?

Sabemos que a reciclagem isoladamente não é a solução para os problemas ambientais, mas contribui de modo considerável para a junção de fatores que contribuirão para os cuidados com o meio.

Deste modo o intuito do presente artigo é difundir a arte do scrapbooking como ferramenta de educação ambiental, demonstrando a possibilidade de elaborar livros, álbuns do momento, com elementos que seriam descartados no lixo.

Uma união da milenar técnica scrapbooking à educação ambiental, adequando a arte com reutilização de elementos de descarte corriqueiro.

O livro, álbum scrapbooking foi produzido com a utilização de resíduos urbanos que se transformaram em elemento de educação ambiental e geraram um produto final objeto apreciável, que une a educação ambiental com a arte, capaz de estimular no cidadão a criatividade, o trabalho manual e a redução de objetos que seriam descartados nos lixões.

A pagina apresentada segue como modelo da produção de uma folha do álbum de fotografia elaborado a partir da utilização de resíduos urbanos empregada a técnica do scrapbooking.

É certo que a arte do scrapbooking não dará sozinha conta de preservar e resgatar os males causados por séculos da ação do homem sobre o meio, porém é possível que sendo difundida no ambiente escolar e/ou em instituições sociais como mais uma estratégia artística de preservação e valorização do meio ambiente, bem como uma forma dos sujeitos expressarem seus sentidos e sentimentos sobre a vida com possibilidade de geração de renda. Inseri-la na educação como forma de "educar para a vida", seja como conteúdo da disciplina de artes, seja como conteúdo da disciplina de meio ambiente; resultará em uma relação mais respeitosa das pela natureza e mais crítica em relação ao consumo e ao descarte de objetos. 


\section{Referências}

AZEVEDO, F. A educação e seus problemas. 4.ed. São Paulo; Melhoramentos, 1948

BRANCO, V.R.C. Os efeitos da globalização na economia: sua relação com o emprego, a educação e a família brasileira. 2010. Disponível em: <http://www.ebah.com.br/content/ABAAAfT3cAF/evolucao-capitalismo>.

Acesso em: 14/11/14.

BUFFA, E.; ARROYO, M.; NOSELLA, P. Educação e cidadania: quem educa o cidadão? 14.ed. São Paulo: Cortez, 2010

BRASIL, A.M.; SANTOS, F.; SIMÃO, L.K. Equilíbrio ambiental e resíduos na sociedade moderna. 4.ed. São Paulo: Brasil Sustentável Editora, 2011

CANDAU, V.M. (organizadora). Sociedade, educação e cultura(s): questões e propostas. 1ed. Petrópoles, RJ: Vozes, 2002

CARVALHO, I.C.M. Educação ambiental: a formação do sujeito ecológico. 2.ed. São Paulo: Cortez, 2006

COSTA, M.C.C. Sociologia: introdução à ciência da sociedade. 3.ed.rev. e ampl. São Paulo: Moderna, 2005

DIAS, G.F. Educação ambiental: princípios e práticas. 9. ed. São Paulo: Gaia, 2004.

DIAS, G.F. Atividades interdisciplinares de educação ambiental: praticas inovadoras de educação ambiental. 2. Ed. rev., ampl. E atual. São Paulo: Gaia, 2006

DINIZ, C. Historia do scrapbooking. Disponível em $<$ http://forum.digiscrappersbrasil.com.br/showthread.php/309-Hist\%C3\%B3riado-Scrapbooking-Por-Cristiane-Diniz>. Acessado 23/09/2014

DUARTE JUNIOR. J.F. Por que art-educação? 6.ed. São Paulo: Papirus, 1991

FREITAS, Eduardo. Os problemas derivados do capitalismo. 2012. Disponível em: <http://www.ebah.com.br/content/ABAAAfT3cAF/evolucaocapitalismo $>$. Acesso em: 14/11/14.

FUSARI, M.F.R. FERRAZ, M.H.C.T. Arte na educação escolar. 2.ed. São Paulo: CORTEZ, 2001

MACHADO, P.A.L. Direito ambiental brasileiro. 15. ed. São Paulo: Malheiros, 2007.

MESZÁROS, I. A educação para além do capital. 2.ed. São Paulo: Boitempo, 2008

PHILIPPI JR., A.; PELICIONI, M.C. Educação Ambiental e sustentabilidade. 1.ed. São Paulo: Manole, 2005 
SUNG, J.M. Se Deus existe, por que ha pobreza?: a fé crista e os excluídos. São Paulo: Paulinas, 1995. Disponível em: <http://www.ebah.com.br/content/ABAAAfT3cAF/evolucao-capitalismo $>$. Acesso em: 10/09/2015

TASSARA, H.; TASSARA, E. (org). BURG, R. (fotos). Dicionário Socioambiental: ideias, definições e conceitos. São Paulo: FAARTE Editora, 2008.

TOZZI, R.H.B.B. As Teorias do Risco na Responsabilidade Civil Ambiental. Disponível em: <http://www.lex.com.br/doutrina 24857023 AS TEORIAS DO RISCO NA R ESPONSABILIDADE CIVIL AMBIENTAL.aspX>. Acesso em 19/11/2014 